\title{
Modelagem volumétrica e simulação de fluxo em arenitos análogos a reservatórios profundos: exemplo da Formação Campo Mourão, Bacia do Paraná
}

\author{
Marcelo Kulevicz Bartoszeck ${ }^{1}$, Sidnei Pires Rostirolla ${ }^{1}$, Adriane Fátima de Campos $^{1}$ \& \\ Álvaro Muriel Lima Machado ${ }^{1}$
}

\begin{abstract}
Resumo Neste trabalho, foi realizada a modelagem de análogos aflorantes, para geração de um conjunto de informações de alta resolução e teste de simulação de fluxo (gás). As atividades compreenderam o levantamento sísmico de alta resolução e o estudo de poços rasos e afloramentos, com a elaboração de modelos geologicamente robustos em áreas aflorantes, análogas àquelas produtoras de hidrocarbonetos em subsuperfície. A área de estudo contém afloramentos do Grupo Itararé, Bacia do Paraná, localizados no município de Ponta Grossa - PR, próximo ao Parque Estadual de Vila Velha. O modelo geométrico foi criado com o auxílio de sísmica 2D de alta resolução, adquirida com fonte artificial do tipo rifle. As linhas processadas possuem de 250 a 700 metros de comprimento, com profundidade de investigação de aproximadamente 200 metros. Os dados sísmicos foram carregados em projeto sísmico para o rastreamento de horizontes e falhas, com a geração de modelos sólidos onde foram atribuídos valores de permoporosidade obtidos por meio da análise de afloramentos, poços rasos e simulação de fácies. As propriedades de porosidade e permeabilidade para a simulação de fluxo foram extraídas através de ensaios físicos em testemunhos dos poços rasos e amostras retiradas dos afloramentos. A simulação de fluxo foi executada em um programa de livre distribuição, com o desenvolvimento de um programa computacional em ambiente Delphi para transformações e adaptações dos dados para inserção no simulador.
\end{abstract}

Palavras-chave: Modelagem, Simulação, Grupo Itararé.

\begin{abstract}
Volumetric modeling and flow simulation in sandstones analogous to depth reservoirs: example of Campo Mourão Formation, Paraná Basin. Analog modeling of high resolution data was done into an approach for flow simulation (gas). High resolution seismic, outcrop information and shallow wells were used in an integrated framework to generate computational geological models. The study area is located near Ponta Grossa city, where rocks of Itaraté Group, Paraná Basin, outcrops with good analog relationship to real hydrocarbon reservoir from depth portions of the same basin. The 2D seismic, acquired with gun-fire seismic source, proved to be helpful to build a volumetric model. The seismic lines are between 250 and $700 \mathrm{~m}$ of length and about $200 \mathrm{~m}$ of depth penetration. Seismic data was load into a computational environment for interpretation of faults and horizons. Solids models are filled with petrophysical values obtained in outcrops samples analysis. The flow simulation runs within a freeware simulator after some translations in files formats done by an in-house software.
\end{abstract}

Keywords: Modeling, Simulation, Itarare Group

INTRODUÇÃO A simulação de fluxo em reservatórios de hidrocarbonetos depende de dois fatores fundamentais: a geometria das unidades de fluxo e as propriedades petrofísicas internas do meio. Usualmente, para reservatórios profundos, a geometria é obtida com imageamento sísmico convencional e com a correlação entre poços. Neste caso, há uma restrição na representatividade geométrica dos dados, com a sísmica convencional apresentando resolução da ordem de 4 a 5 dezenas de metros e os poços da ordem de decímetros a poucos metros. A modelagem petrofísica, por outro lado, apresenta restrições de caráter amostral, sendo fortemente dependente de haver testemunhos e da qualidade dos logs geofísicos presentes. Com o propósito de suprir a deficiência na resolução dos dados convencionais, permitindo o teste de hipóteses e a geração de diferentes cenários, neste trabalho foi utilizada a modelagem de afloramentos análogos às condições de subsuperfície. Os resultados compreendem a simulação computacional de fluxo (gás), com base no estudo de afloramentos do Grupo Itararé, Bacia do Paraná, localizados no município de Ponta Grossa - PR. No local avaliado, aflora uma secão areno-pelítica da Fm. Campo Mourão, em condições faciológicas bastante semelhantes ao reservatório da acumulação de Barra Bonita, cuja analogia em termos estratigráficos foi discutida em 
Vesely et al (2007). A seção sedimentar apresenta intenso fraturamento, cujo registro e processos estruturais foram discutidos em Rostirolla et al (2001) e Kraft et al (2003). O modelo geológico foi criado no programa Petrel (Schlumberger, www.slb.com - licença acadêmica) a partir da interpretação sísmica de alta resolução e sua integração com informações de campo. As seções sísmicas $2 \mathrm{D}$ foram adquiridas com fonte artificial do tipo rifle, resultando em linhas processadas com 250 a 700 metros de comprimento e profundidade de investigação de aproximadamente 200 metros. A qualidade sísmica é baixa ou média, devido às variações laterais de velocidade, presença de falhas e contaminação por ruídos coerentes de aquisição. Estes dados sísmicos foram carregados num projeto sísmico com visualização $2 \mathrm{D}$ e 3D para a interpretação de horizontes e falhas, cujas propriedades permoporosas foram extraídas através de ensaios físicos em amostras de testemunhos dos poços rasos e de afloramentos. A simulação de fluxo foi executada no programa Boast (www.netl.doe.gov), de livre distribuição, sendo também necessário o desenvolvimento de um programa em ambiente Delphi (http:// www.codegear.com/) para transformações e adaptações dos dados para inserção no simulador.

INTERPRETAÇÃO SÍSMICA A dificuldade em produzir dados sísmicos rasos com alta qualidade é inerente à aquisição de dados de alta resolução, que contêm alta freqüência e cujos ruídos apresentam espectro semelhante ao sinal sísmico real. As fontes disponíveis têm relativo sucesso na geração de freqüências acima de $100 \mathrm{~Hz}$, entretanto ocorre uma atenuação nas camadas superficiais de solo que reduzem drasticamente as possíveis reflexões que retornariam aos geofones. Outro aspecto negativo consiste na interferência dos ruídos coerentes como ground-roll e ring da refração, que coincidem no sismograma com a janela de reflexões. Não obstante tais problemas, a interpretação sísmica foi fundamentada em diferenças de sismofácies entre alguns poucos refletores, onde havia maior confiabilidade no sinal sísmico.

As seções sísmicas inseridas no projeto de interpretação (Fig. 1) foram distribuídas o mais eqüidistante possível, com o objetivo de cobrir toda a área de interesse. O espaçamento médio entre linhas foi de 40 metros, com a malha definida na posição transversal ao sistema de fraturas dominante. Algumas linhas de controle foram adquiridas com sentido oblíquo, para amarração de refletores em todo o bloco interpretado.

Os critérios utilizados para a discriminação de camadas incluíram a caracterização de sismofácies, continuidade lateral de refletores e a amarração em tempo das associações faciológicas observadas em levantamentos de campo. A figura 2 mostra as feições marcantes que auxiliaram na divisão vertical durante a interpretação sísmica. As falhas foram interpretadas em descontinuidades em inflexões dos refletores e onde havia difração ou espalhamento do sinal.

Pode-se observar, em dois exemplos de linhas sísmicas interpretadas, que a qualidade do dado é baixa.

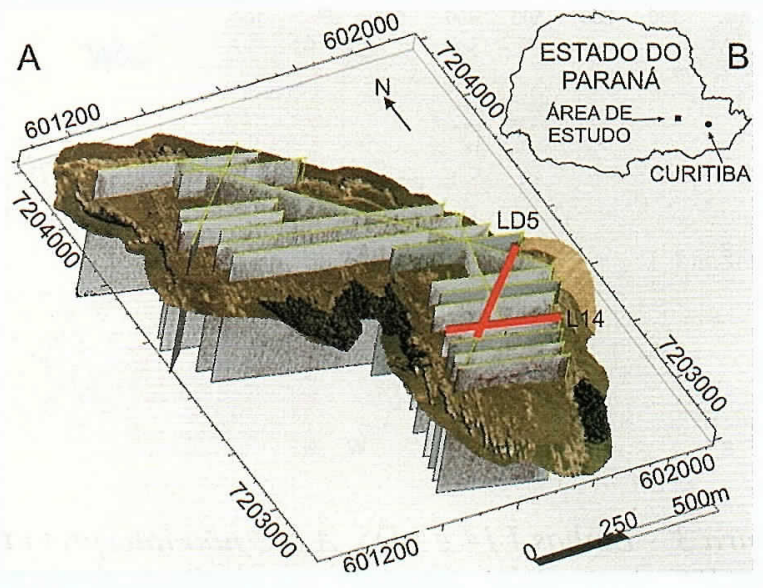

Figura 1 - Foto aérea com as seções sísmicas da área de estudo.

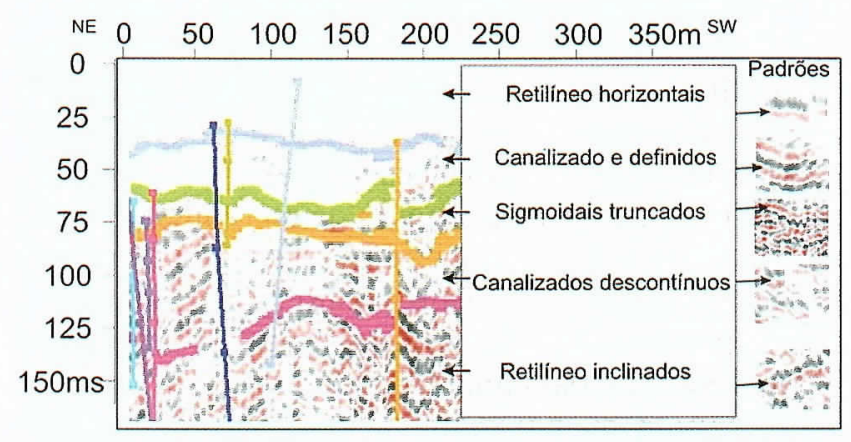

Figura 2 - Exemplos de critérios para interpretação de horizontes sísmicos.

Entretanto, alguns refletores em torno de $30 \mathrm{~ms}$ a $130 \mathrm{~ms}$ que apresentam pequena continuidade lateral quando analisados individualmente, no conjunto mostram repetições do padrão existente em seções próximas, o que reforça sua existência como intervalo estratigráfico significativo.

A linha L14 tem direção E-W (visualização para sul), com cerca de 250 metros de comprimento após o empilhamento (Fig. 3A). O primeiro refletor corresponde à primeira quebra do registro estratigráfico no local, no topo da Unidade C. O segundo refletor corresponde ao topo da unidade B, o terceiro refletor corresponde ao topo da Formação Lagoa Azul, e finalmente o quarto refletor ao topo da Formação Ponta Grossa.

A Linha LD5 tem direção N-S (com visualização para leste) e cerca de 450 metros de comprimento após o empilhamento (Fig. 3B). A continuidade das interpretações dos 4 refletores seguiu como critérios a interseção com diversas linhas de sentido E-W e os padrões de reflexão semelhantes aos encontrados em linhas sísmicas próximas.

\section{MODELAGEM GEOMÉTRICA}

Modelagem de falhas $\mathrm{Na}$ área mapeada predominam arenitos e, secundariamente, pelitos com grande quantidade de fraturas (Rostirolla et al 2001, Kraft et al, 2003, Trsazkos et al 2005), relacionadas a um sistema 


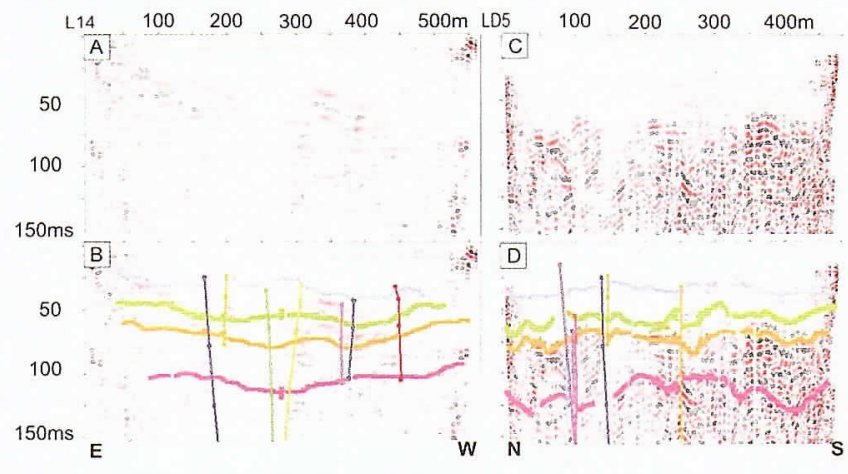

Figura 3 - Linhas L14 e LD5. A e C não interpretadas e B e D interpretadas, respectivamente L14 e LD5. Localização das linhas L14 e LD5 na figura 1.

deformacional de caráter distensivo a transcorrente. O rejeito das falhas é de decímetros a poucos metros, havendo dificuldade em sua visualização sísmica, devido ao deslocamento quase imperceptível de refletores. $\mathrm{Na}$ maioria das vezes, as falhas são representadas por faixas verticais ou com alto ângulo de mergulho, onde há perdas ou sombras de sinal, reffetindo o espalhamento ou difração da onda. O rastreamento das falhas foi realizado após o traçado dos horizontes, com a subseqüente transformação para pilares.

A modelagem computacional no programa Petrel é baseada no conceito de pilares, que são entidades relacionadas a superfícies que tenham correlação com falhas, onde cada par de pilares forma um plano. Existem pilares do tipo vertical, com 2 pontos, 3 pontos ou mais, inseridos por 1, 2 ou mais pontos, dependendo do tipo selecionado. A cada novo pilar adicionado em uma mesma falha, automaticamente será criado um novo plano de falha, e serão conectados os pilares com linhas simulando este plano. Ajustes de inclinação dos planos de falha são necessários para corroborar o modelo conceitual do estilo tectônico interpretado. Independente do meio utilizado para se chegar aos "pilares" de falha, é pré-requisito a existência deste tipo de objeto para a continuidade da modelagem. Essas diversas opções para a criação de falhas visam aproximar o modelo computacional o máximo possível da realidade geológica vista no campo. Entretanto a complexidade das estruturas tectônicas e sua inter-conectividade são difíceis de se modelar computacionalmente de forma rápida e que os simuladores de fluxo assimilem todo o detalhamento. Após todas as falhas serem interpretadas e transformadas em pilares, pode-se realizar a etapa de geração do esqueleto. $\mathrm{O}$ produto desta etapa consiste em 3 superfícies, topo, meio e base (Fig. 4).

Zoneamento vertical Nas seções sísmicas, podem ser caracterizadas cinco camadas, que corroboram a divisão litoestratigráfica observada em campo. Com base no padrão de sismofácies, as quatro camadas superiores podem ser interpretadas como associações faciológicas e são correlacionadas a intervalos estratigráficos das formações Lagoa Azul e Campo Mourão, do Grupo Ita-

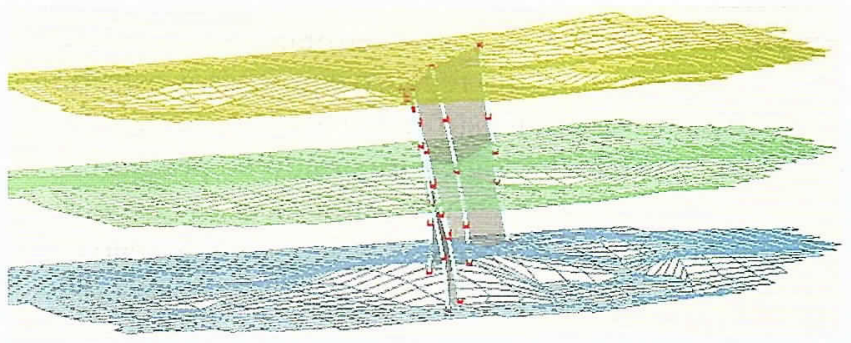

Figura 4 - Resultado no Petrel do procedimento de Pillar Gridding, um esqueleto (topo, meio e base) diretamente relacionado com as falhas interpretadas.

raré. A camada basal corresponde à porção superior da Fm Ponta Grossa.

O método consiste em inserir superfícies no esqueleto do modelo $3 \mathrm{D}$, a partir do rastreamento sísmico de horizontes. Nesta etapa as superfícies terão sua estrutura atrelada a todas as definições geométricas que o modelo possui, permitindo a extrapolação matemática para seu preenchimento. Assim, podem ser inseridos os contatos entre unidades geológicas, materializadas as superfícies, o tipo de relação deposicional como: erosional, descontínua, basal ou concordante.

Nesta etapa da modelagem 3D é definido um esqueleto, são inseridas as falhas e os principais horizontes. O que se espera deste processo de modelagem seria algo semelhante à figura 5 , onde as zonas operacionais ou camadas podem ser continuamente subdivididas, para representar informações faciológicas pertinentes. Este processo deve chegar numa escala de detalhe suficiente, em termos de tamanho compatível com as unidades de fluxo pretendidas.

MODELAGEM DE PROPRIEDADES Após o arcabouço geométrico construído, o modelo $3 \mathrm{D}$ possui condições para que as unidades volumétricas (voxels) sejam preenchidas, com valores relacionados à geologia ou a características matemáticas do próprio modelo. Programas de modelagem oferecem métodos consagrados como krigagem ou Inverso do Quadrado da Distância. Mas também existem métodos determinísticos e estocásticos que podem fornecer valores a todos os voxels sem qualquer dado de entrada. Estes métodos que modelam propriedades a partir de regras são necessários para que se completem informações conceituais não mensuráveis, como por exemplo geometrias externas de estratos, fácies deposicionais e outros que normalmente fazem parte das descrições realizadas em afloramentos pelos geólogos de campo. Programas de modelagem de propriedades oferecem funções parecidas a estas (Tab. 1).

Modelagem geométrica de corpos sedimentares Como mostrado anteriormente, foi realizada a interpretação das seções sísmicas e, a partir delas, foram definidas 5 zonas para o modelo deste estudo. Na modelagem geométrica dos estratos internos, cada zona foi subdividida e preenchida com formas geométricas 


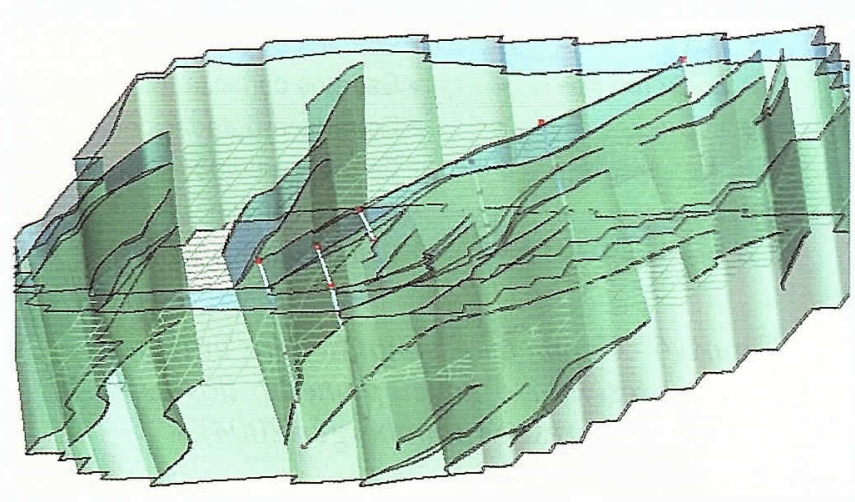

Figura 5 - Zoneamento vertical realizado no procedimento do "make zones" com as principais camadas estratigráficas.

e estas foram associadas a determinadas geometrias dos corpos, observados em trabalhos de campo. Desta forma cada geometria representa o envelopamento dos estratos sedimentares, que ocorrem em posições estratigráficas conhecidas. As formas geométricas utilizadas e sua associação com as geometrias de campo podem ser visualizadas na figura 6 .

Três das cinco zonas foram modeladas de acordo com características individualizadas com mais de uma forma geométrica. Nas zonas 3 e 5 foi realizada a modelagem geométrica dos estratos apenas com um tipo de forma. A descrição sucinta de cada zona e seu preenchimento com este exemplo de propriedade pode ser acompanhada a seguir.

ZONA 1 Inicialmente foram gerados os corpos com a forma de elipse e tabulares, referentes à zona 1, sem utilizar qualquer parâmetro de distribuição vertical ou areal. Através dos dados de campo, sabe-se que estruturas como estratificações cruzadas e canais encontram-se preferencialmente na base desta unidade. Na seqüência foram geradas funções de probabilidade de ocorrência desta da forma geométrica dos corpos para cada corpo existente nesta zona. As funções de probabilidade levaram em consideração a variação de espessura desta zona, que está em torno de $20 \mathrm{~ms}$. Na função de probabilidade adotada, a forma de elipse apresenta probabilidade 1 para espessuras pequenas, decaindo até chegar valores quase nulos em espessuras maiores que $12 \mathrm{~ms}$. Na forma de Box apresenta probabilidade 1 para espessuras grandes, decaindo os valores em espessuras menores do que $12 \mathrm{~ms}$. Como resultado deste procedimento, observa-se que os corpos representativos da forma elipse ocorrem de forma preferencial na base desta zona, diferentemente da primeira simulação, que sua ocorrência aparentava aleatoriedade. Proporcionalmente ao volume total desta zona, a forma Box representa $75 \%$ do total, dominando a distribuição mesmo nas espessuras menores.

ZONA 2 Na zona 2 a simulação das formas geométricas de corpos apresentou maiores dificuldades. Através da analise dos dados de campo, estipulou-se que na zona 2 ocorrem três formas geométricas de corpos: half elipse, elipse e lower half pipe. A função de probabilidade destinada a preencher a porção média desta zona teve que envolver um intervalo maior de espessura, sobrepondo-se em mais de uma faixa. Inicialmente a modelagem geométrica dos estratos foi realizada sem parâmetros de distribuição vertical ou areal. Na seqüência foram aplicadas funções de probabilidade de distribuição vertical para esta zona, para os três tipos de formas geométricas relacionados. O resultado demonstra que a forma de lower half pipe ocorreu principalmente na porção basal desta zona, corroborando a função de probabilidade atribuída a mesma. As duas outras formas (elipse e half elipse) apresentaram uma distribuição preferencialmente na porção superior da zona. Apesar da forma elipse ter sido programada pela função de probabilidade para ocorrer somente na porção superior desta zona, foram observadas algumas anomalias na sua base. Uma possível causa deste problema é o fato desta zona possuir apenas duas subdivisões na vertical,

Tabela 1 - Modelagens e objetivos para geração de propriedades no modelo $3 D$.

\begin{tabular}{l|l}
\hline Tipos de modelagem & Objetivo \\
\hline Modelagem geométrica & $\begin{array}{l}\text { Funções pré-definidas para gerar propriedades como Bulk Volume, profundidade, espessura acima } \\
\text { de um contato, enfim valores que tem correlação com a forma das unidades volumétricas. }\end{array}$ \\
\hline Viés em poços & $\begin{array}{l}\text { Transfere os valores de curvas geofísicas ou pretrofísos laboratoriais de testemunhos dos poços } \\
\text { para as células. }\end{array}$ \\
\hline Modelagem de fácies & $\begin{array}{l}\text { Definidos métodos de extrapolação determinísticos e ou estocásticos de controle, por exemplo } \\
\text { a geometria dos corpos (orientação, espessura, largura, forma geométrica), tendências (paleo- } \\
\text { correntes, linhas de fluxo), ambientes (fluvial, canais, planícies de inundaçã), Drifts (tendências } \\
\text { extrapolações fractais). Este processo é executado no sentido de condicionar a interpolação das } \\
\text { propriedades continuas como porosidade e permeabilidade a descrições deterministicas. }\end{array}$ \\
\hline Modelagem Petrofísica & $\begin{array}{l}\text { Consiste basicamente em extrapolar propriedades ao longo do modelo, utilizando métodos } \\
\text { determinísticos ou estocásticos bem variados, considerando ou não as fácies modeladas. }\end{array}$ \\
\hline
\end{tabular}


impedindo desta forma uma boa resposta das funções de probabilidade atribuídas para a ocorrência de cada tipo de forma geométrica dos corpos.

ZONA 4 Na zona 4 ocorrem duas células de espessura máxima e dois tipos de formas geométricas de corpos, retirados a partir dos de campo, para preencher o volume. Neste sentido a modelagem geométrica dos estratos, e suas funções de probabilidades tornam-se mais simples. Inicialmente a modelagem desta zona foi realizada sem o viés matemático de distribuição vertical, em que a forma Box ocorre tanto na base como no topo desta zona. Para uma melhor distribuição das formas de corpo na vertical desta zona, foram utilizadas as duas funções de probabilidade da base para o topo. Como resultado, as formas geométricas do tipo Box ocorreram preferencialmente no topo desta zona.

Modelo completo O principal resultado da utilização de funções de probabilidade na distribuição vertical pode ser observado na figura 7 .

Esta figura apresenta uma distribuição mais tabular após o viés vertical, melhorando a similaridade da modelagem geométrica dos estratos com os dados de campo. O modelo completo considera as formas geométricas de corpos escolhidas para representar tanto as geometrias externas como internas das camadas pode ser visualizado na figura 8 .

Modelagem de fácies deposicionais Na definição de fácies foi utilizado a classificação proposta por Eyles \& Miall (1984), na qual são atribuídas letras que correspondem ao litotipo e à estrutura deposicional predominante. A estratigrafia do local de estudo foi adaptada a partir do trabalho de Vesely 2006, Vesely et al (2007) e Bocardi (em preparação).

No local de estudo, as zonas 1, 2 e 3 apresentaram variações de fácies mais acentuadas que as zonas 4 e 5 . Nas zonas superiores foi necessário aumentar o número de subdivisões para contemplar uma discretização mais especifica das fácies. Por exemplo: na zona 1 existiam 2 formas geométrica de corpos sedimentares para serem distribuídas em 3 subdivisões verticais internas. Porém existem 4 tipos de fácies para as mesmas 3 divisões, sendo necessário criar mais um nível de divisão vertical. Segue abaixo a descrição da distribuição de fácies nas zonas modeladas:

ZONA 1 Para a Zona 1 foram distribuídas quatro fácies (Sh, Sm, Sg e Fl), com as respectivas proporções e probabilidade de ocorrência vertical. O resultado da modelagem de fácies da zona 1 é apresentado na figura 9. Nota-se que a fácies Sh manteve concentração maior no topo da zona 1 representando o modelo estratigráfico de distribuição espacial propostos.

ZONA 2 Na zona 2 foram distribuídas cinco fácies (Sp, Sm, Fla, Sg e Flb), com funções de probabilidade e proporções específicas para cada fácies. A figura 10 apresenta a modelagem de fácies para a zona 2 . Nota-se

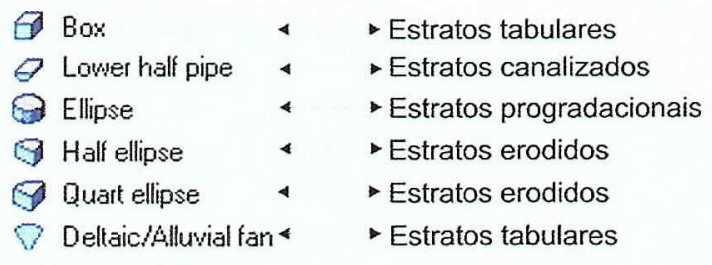

Figura 6 - Geometrias simplificadas utilizadas para representar o envelopamento dos estratos sedimentares (Schlumberger 2004).

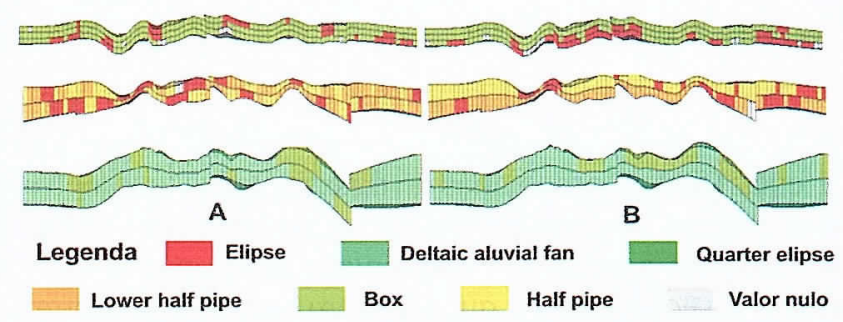

Figura 7 - Comparação entre duas modelagens, em que na seleção $A$ as zonas foram preenchidas sem uma função de distribuição vertical, e em $B$ as mesmas zonas utilizaram um viés externo baseado na probabilidade de ocorrência em relação a posição na espessura total de cada zona.

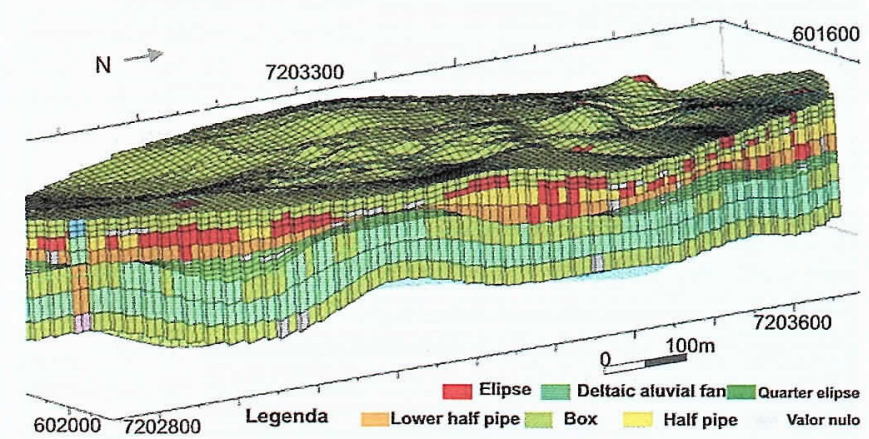

Figura 8 - Modelo 3D completo com todas as zonas e a classificado por cores diferenciadas as formas de corpos geométricos que contém cada célula.

que no caso da zona 2 ocorrem duas camadas internas

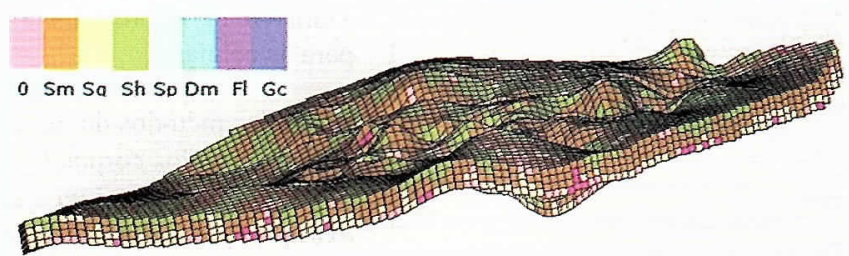

Figura 9 - Resultado da distribuição de fácies na zona 1 . 
com predominância da Fácies Fl. Neste caso particular as camadas foram nomeadas de Fla e Flb. Assim como cada uma dessa camada Fl possuiu uma função de distribuição vertical particular de acordo com sua posição espacial na estratigrafia.

ZONA 3 Na zona 3 foram relacionadas três fácies ( $\mathrm{Sm}$, Gc e Dm), com proporções e funções de probabilidade específicas para cada fácies. O resultado da modelagem de fácies para a zona 3 é apresentado na figura 11. Nota-se que as funções de probabilidade possuem áreas em comum, ou seja não são totalmente contrastantes, e portanto a fácies Dm foi distribuída principalmente na base mas também alguns voxels do topo foram assinalados com esta fácies.

Discretização de propriedades O conjunto de informações discretizadas, obtidas a partir das características geométricas e fáciológicas de cada zona, foram inseridas no modelo 3D para correlação com a porosidade e a permeabilidade. Neste sentido, foram geradas subpropriedades para as zonas, com objetivo de transformar a codificação interna do modelador para uma simplificação booleana. Ou seja, para cada forma geométrica dos corpos, foi indicada a ausência ou presença de uma determinada forma geométrica. A multiplicação desta subpropriedade por outra discretização, no caso ausência ou presença de uma fácies, resultará num terceiro produto que será então multiplicado pelo valor determinístico das propriedades petrofísicas (Fig. 12). O valor zero desta figura representa todas as células que não contém a forma de corpo elipse na zona 1. Caso alguma nova propriedade seja gerada, e que nesta somente as células com elipse serão utilizadas, o modelo desta figura será base para este procedimento. A figura 13 apresenta a distribuição da forma geométrica elipse, com uma filtragem para eliminar os valores nulos, presentes na imagem anterior, e assim possibilitar a visualização do comportamento das fácies somente nos corpos geométricas em elipse.

Modelagem de propriedades petrofísicas Como continuidade aos processos integrados de modelagem, e tendo como objetivo concreto definir parâmetros para a simulação de fluxo, foi executada uma associação direta de propriedades físicas, como porosidade e permeabilidade, presentes numericamente em cada célula. Através de ensaios físicos com amostras recolhidas nos afloramentos e em poços exploratórios rasos foram determinadas algumas relações entre a porosidade e as fácies. A porosidade possui uma variação vertical acentuada nas fácies e esta característica deve ter influência no comportamento do reservatório. A figura 14 mostra algumas relações observadas entre as fácies e as porosidades.

Cada fácies possui um comportamento diferenciado em termos de propriedades petrofísicas, baseadas nas feições primárias e evolução diagenética da rocha. Além das estruturas internas, a textura também é um fator determinante para diferenciar estratos semelhantes

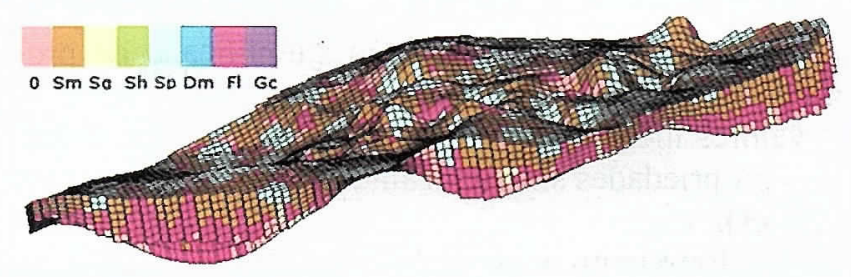

Figura 10 - Resultado da distribuição de fácies na zona 2.

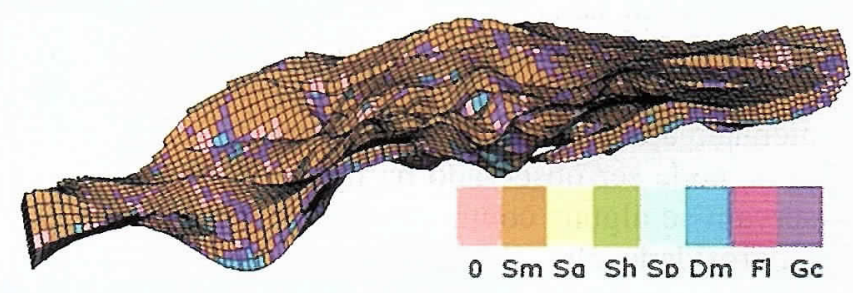

Figura 11 - Resultado da distribuição de fácies na zona 3.

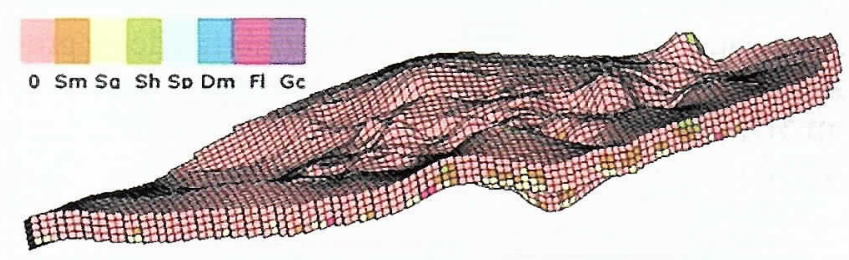

Figura 12 - Após a discretização é possível visualizar a distribuição de determinada propriedade baseada em outra propriedade, permitindo operações matemáticas entre voxels.

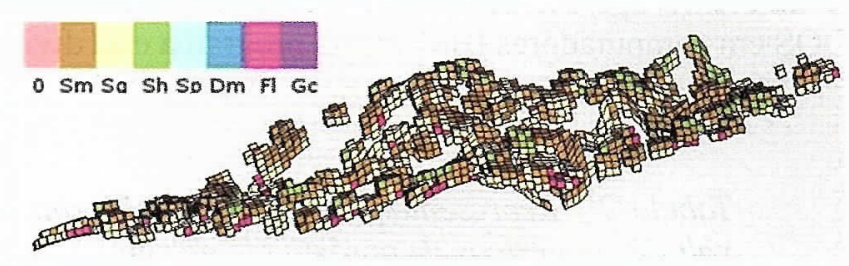

Figura 13 - Representação com transparência nas células que não contenham a propriedade forma geométrica de corpos do tipo elipse.

em termos de geometria de corpos e fácies. Utilizando um exemplo com 5 zonas, a forma geométrica elipse, associada a fácies $\mathrm{Sm}$, pode ter um comportamento físico diferenciado em determinada porção da estratigrafia local. Esta variação no comportamento petrofísico é obtida através dos modelos de associação de fácies e conseqüentes processos deposicionais atuantes, e seu produto direto em termos de maturidade. No caso da zona 1 as formas de corpos elipses têm relação com elementos geométricos do tipo sigmoidal, progradantes, e as formas do tipo Box a plano-paralelas, que são relacionadas a processos que envolvem fluxos gravi- 
tacionais. A partir desta relação simplificada de propriedades de interesse, pode-se visualizar na tabela 2 os valores indicados para cada célula que contenha as duas propriedades simultaneamente (forma geométrica e fácies).

Entretanto para células que contenham a forma geométrica tipo elipses e fácies $\mathrm{Sg}$, ocorre uma gradação normal, onde provavelmente o topo possui valores de porosidades menores do que a sua base. Desta forma foi definida uma função simples, determinando a espessura da zona no eixo horizontal e o valor de porosidade (em percentagem) no eixo vertical. O resultado da modelagem da porosidade nas células que contenham apenas as formas geométricas de corpo tipo elipses, pode ser observado na figura 15 . Nesta figura observam-se alguns contrastes abruptos de valores de alta porosidade, em células vizinhas com baixa porosidade. Esta situação é uma conseqüência direta do tipo de dado de entrada utilizado nesta modelagem. Existindo um controle por poços, que trazem à tona valores de dependência espacial e distribuição das propriedades petrofísicas, estes contrastes seriam minimizados. Um outro dado que pode suavizar esta variabilidade de propriedades, consiste nos atributos sísmicos, usualmente em 3D, como impedância acústica. Estes dados 3D podem funcionar como uma deriva externa que controlará a modelagem.

\section{SIMULAÇÃO DE FLUXO}

Simulador O simulador de fluxo 3D, denominado Boast, é um programa computacional de domínio público disponibilizado pelo Departamento de Energia dos Estados Unidos. A primeira versão do Boast foi lançada em 1982 e a última atualização ocorreu em 1993. O ambiente operacional para executar o programa é DOS em computadores IBM/PC. O programa está divi-

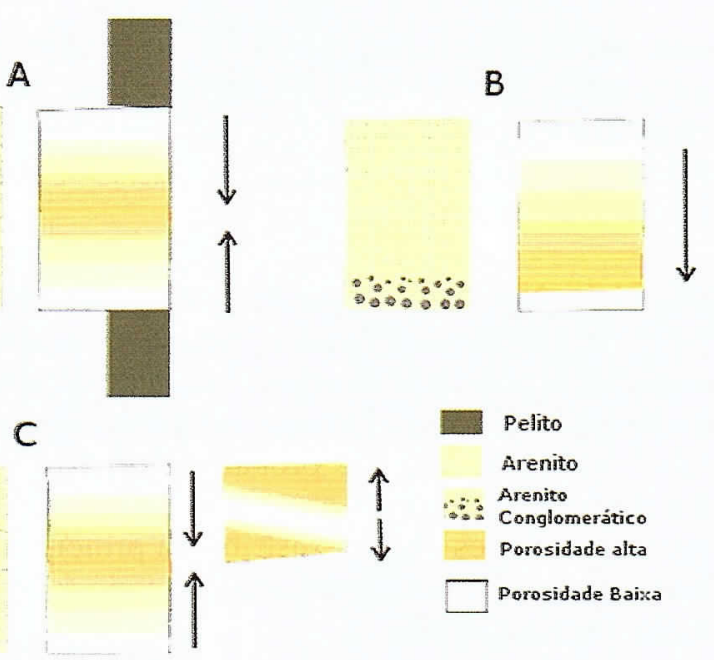

Figura 14 - Distribuição da porosidade de acordo com as principais fácies. $A$ - Sm - arenito maciço; $B$ - Sh arenito laminado; $C$ - $S g$ - arenitos com gradação normal. A setas indicam o aumento de porosidade. Sendo que a fáceis Sh apresenta comportamento variado de porosidade de acordo com a inclinação das laminações (adaptado de Bocardi, em preparação).

dido em dois módulos principais: o Boast que executa a simulação e o EdBoast que configura os parâmetros do reservatório. Essencialmente são utilizados arquivos ASCII para inicialização e na geração dos resultados.

Este programa comporta até três fases distintas no fluido, em qualquer proporção, e utiliza na simulação a Lei de Darcy isotérmica em 3D, assumindo que todos os fluídos contidos no reservatório podem ser descritos nas fases óleo, gás e água. As composições das fases são consideradas constantes e as proprieda-

Tabela 2 - Representação da associação entre a forma geométrica de corpos e as fácies e os valores numéricos de porosidade na zona 1.

\begin{tabular}{l|l|l|l}
\hline $\begin{array}{l}\text { Forma Geométrica } \\
\text { dos corpos }\end{array}$ & fácies & porosidade & características \\
\hline \multirow{4}{*}{ Elipse } & $\mathrm{Sm}$ & $15 \%$ & Maciço, médio, imaturo, estratos truncados \\
\cline { 2 - 4 } & $\mathrm{Sg}$ & $\begin{array}{l}10 \%-\text { topo } \\
20 \% \text { - base }\end{array}$ & Gradação normal, estratos truncados, médios a grossos \\
\cline { 2 - 4 } & $\mathrm{Sh}$ & $13 \%$ & Laminado médio a fino, estratos truncados \\
\cline { 2 - 4 } & $\mathrm{Fl}$ & $7 \%$ & Estratos escavados por canais \\
\hline \multirow{3}{*}{ box } & $\mathrm{Sm}$ & $18 \%$ & Maciço, médio, imaturo, estratos preservados \\
\cline { 2 - 4 } & $\mathrm{Sg}$ & $\begin{array}{l}12 \%-\text { topo } \\
22 \%-\text { base }\end{array}$ & Gradação normal, estratos preservados, médios a grossos \\
\cline { 2 - 4 } & $\mathrm{Sh}$ & $15 \%$ & Laminado médio a fino, estratos preservados \\
\cline { 2 - 4 } & $\mathrm{Fl}$ & $4 \%$ & Estratos preservados \\
\hline
\end{tabular}


des físicas modificam apenas pela variação de pressão. Os mecanismos que podem ser simulados na recuperação dos hidrocarbonetos são: expansão dos fluidos, migração, drenagem gravitacional e inibição capilar. O simulador utiliza o método de diferenças finitas e solução numérica IMPES (Implicit Pressure-Explicit Saturation). Ele contém tanto técnicas de solução direta ou iterativas (LSOR) para resolver as esquações. As características de modelagem deste simulador são adequadas tanto para um reservatório real como para o estudo de análogos.

Modelos Simulados Visando abordar qual seria a influência das falhas na simulação de fluxo em um reservatório análogo, foram definidos quatro cenários para simulação. Sendo o primeiro sem falhas, o segundo contendo falhas como barreiras, o terceiro com falhas condutoras e o último com falhas em situação intermediária, entre barreiras/condutos. Antes de realizar a simulação, foi utilizado um processo de redução de escala para que a resolução do reservatório fraturado contenha um número de células menor, facilitando o processamento computacional.

Upscaling O modelo integral possuí 257.000 células enquanto o simulado possuí 9.000. Com o processo de upscaling, a distribuição espacial de propriedades petrofísicas sofreu alterações mais significativas em regiões com concentrações de valores anômalos. Intuitivamente ocorre a tentativa de criar um modelo 3D contendo todas as variações geológicas interpretadas em seções sísmicas, dados de poços e no caso de modelagem de análogos as informações de campo. Facilmente estes modelos ultrapassam a casa de 300.000 células, enquanto os programas de simulação sugerem limitar o processamento em no máximo 100.000 células, para otimizar os trabalhos evitando processamentos demorados.

Após o upscaling, o modelo estrutural utilizado para a simulação deve ser o mesmo, contendo as falhas e os horizontes sísmicos, porém com menor resolução. A variação no incremento do plano IJ (equivalente ao plano XY) apresenta pouca mudança no aspecto geral dos dois grids, como pode ser observado na figura 16 .

A princípio, pode parecer que este processo de redução de subdivisões irá prejudicar a forma do modelo 3D, mas o que ocorre é apenas uma simplificação das estruturas de pequeno tamanho, permanecendo o arcabouço geral condizente com o modelo geológico inicial. A figura 17 apresenta o resultado após o procedimento de redução de subdivisões, mostrando a similaridade entre os dois modelos.

Após a redução do número de subdivisões em cada zona, existe a necessidade de correlacionar quais divisões do modelo integral apresentam correspondentes no modelo para simulação. Desta forma pode-se relacionar as divisões 1,2 e 3 da zona 1 do modelo integral com a divisão 1 da zona 1 do modelo para simulação, e assim respectivamente. Assim os valores das propriedades que compõe o topo de uma zona, serão

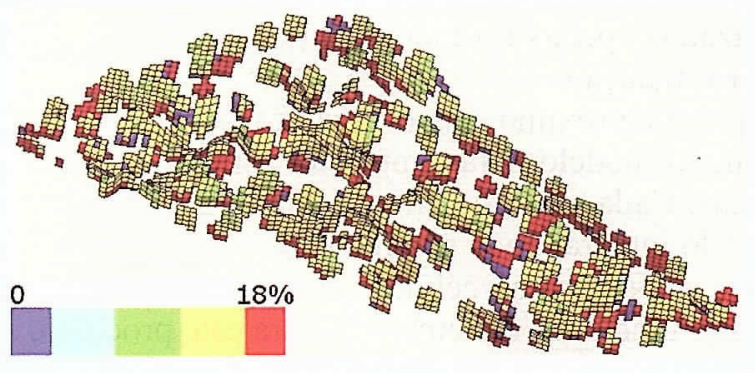

Figura 15 - Porosidade distribuida nas células que contenham elipses.
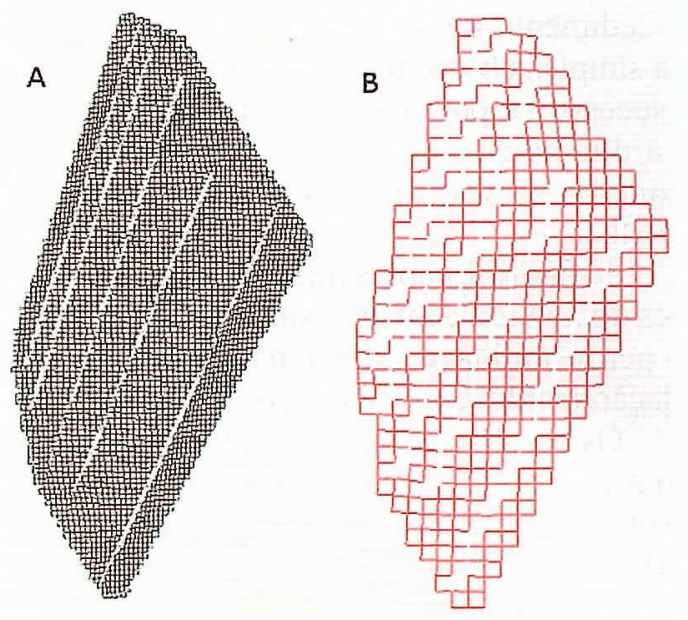

Figura 16 - Aspecto geral do grid com a visualização das estruturas tectônicas (linhas brancas) com incremento de 10 metros (esquerda) e com incremento de 30 metros (direita).

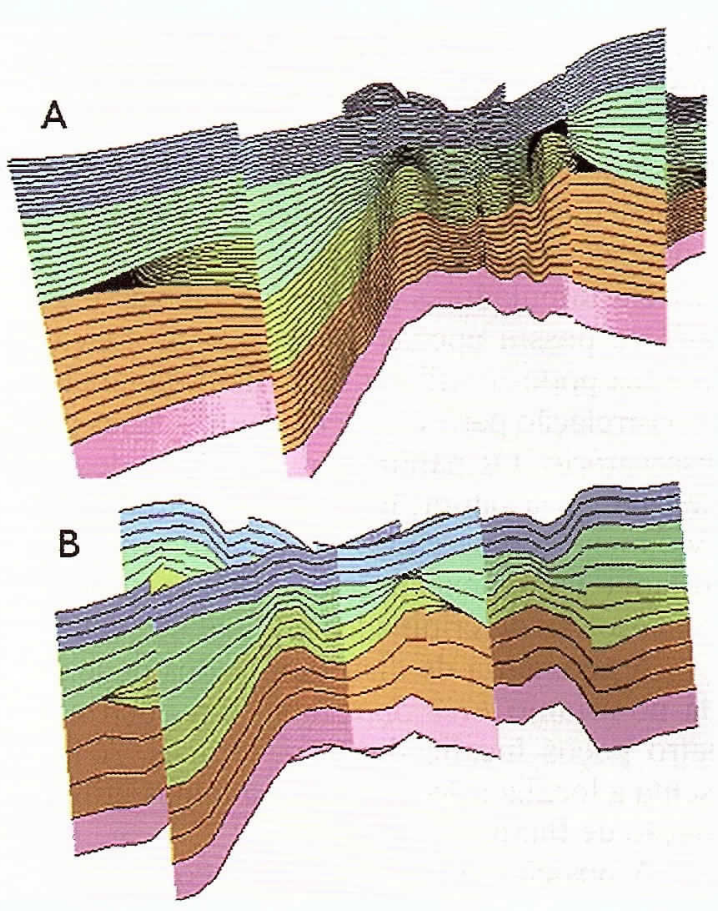

Figura 17 - Seções verticais antes do procedimento de redução de subdivisões (A) e após (B). 
utilizados apenas no topo da mesma zona no modelo para simulação.

O próximo passo consiste no preenchimento do novo modelo para simulação com as propriedades físicas. Cada valor de uma propriedade distribuída no modelo integral pode ser utilizado para determinar um novo valor para as células do modelo de simulação. Existem métodos matemáticos para este processo, sendo os principais baseados em médias dos valores ou na quantificação de vetores, quando a propriedade apresentar valores diferentes para cada direção em IJK. No momento do cálculo das médias pode-se levar em conta um ponderador baseado no volume da célula do modelo integral, que está contido na célula do novo modelo. $\mathrm{O}$ procedimento de upscaling utilizando o método de média simples obteve um resultado razoável, honrando com sucesso as porções com alta porosidade, mesmo após a diminuição significativa do número de células horizontal e na vertical, como pode ser observado na figura 18.

A figura 19 apresenta o resultado do upscaling através do método de média simples para a propriedade física permeabilidade. Também neste caso o modelo de simulação manteve as principais heterogeneidades.

Os resultados finais do processo de upscaling foram a redução de aproximadamente 257 mil células para cerca de 9 mil. As dimensões em IJK reduziram de $57 \times 110 \times 41$ para $19 \times 36 \times 13$, respectivamente

Parametrização do Modelo de Entrada No programa EdBoast os parâmetros utilizados para a simulação foram 19x36x6 de IJK com 30x30x10 pés respectivamente locados a 4000 pés de profundidade. Para cada um dos seis níveis foram inseridos os valores de porosidade e permeabilidade. Os valores de porosidade foram iguais para todos os modelos, apenas os valores de permeabilidade foram alterados em cada situação de comportamento das falhas. Após a definição das propriedades do arcabouço geológico/geométrico do reservatório devem-se determinar quais são as condições físicas de início dos fluídos. Estas condições normalmente são relacionadas com a pressão do reservatório, e são inseridas em simuladores através de tabelas e gráficos. Quando se possui apenas a propriedade física de um dos fluidos pode-se utilizar o artifício de tabelas/gráficos de correlação para se obter as outras fases presentes no reservatório. Os parâmetros são divididos em dois grandes temas: a saturação e os parâmetros PVT (Pressão, Volume e Temperatura). Parâmetros adicionais que controlam o tempo/execução e a locação de poços para a simulação são determinados no final da seqüência.

A geometria de distribuição dos poços foi inspirada no arranjo Five Spot, com um poço no centro e quatro poços localizados nos vértices. A figura 20 apresenta a localização dos poços e falhas utilizados na simulação de fluxo.

A posição em IJ de cada poço é fundamental para amarração com o grid que está sendo simulado. Para que seja verificada a possibilidade de influência maior ou menor da migração lateral do fluido, pode-se

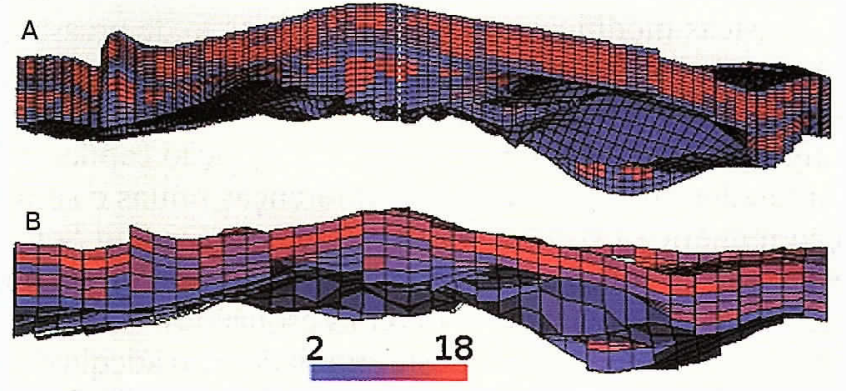

Figura 18 - Distribuição da porosidade no modelo integral (A) e no modelo de simulação (B), escala de cores da porosidade em $\%$.

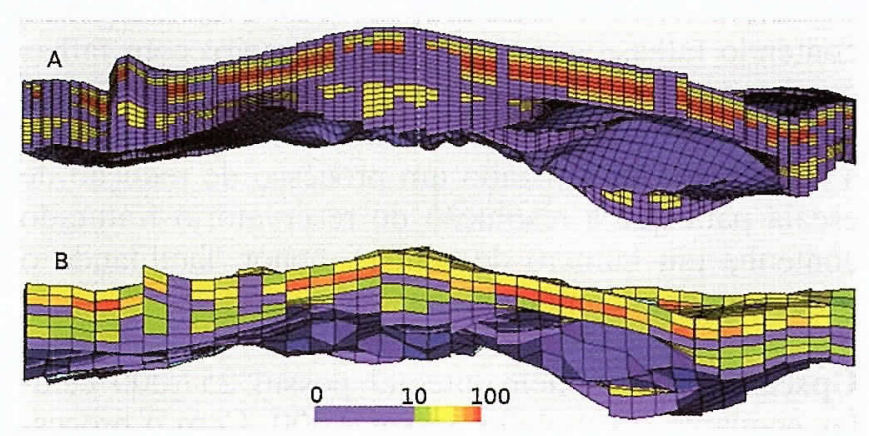

Figura 19 - Distribuição da permeabilidade no modelo integral (A) e no modelo de simulação (B), escala de cores da permeabilidade logarítmica em $\mathrm{mD}$.

locar poço no K superior e no K intermediário. No caso deste modelo no K1 (superior) para todos poços. A tabela 3 possui a locação de cada um dos poços utilizados na simulação.

Simulação Os parâmetros determinados para os diversos fatores que controlam a produção de fluídos em um reservatório foram executados no simulador de fluxo Boast. Os parâmetros inerentes ao reservatório foram os mesmos para todas as simulações, tendo sido modificada apenas a permeabilidade nas zonas de influência das falhas. Desta forma foram totalizadas quatro simulações para o modelo, com arranjo de cinco poços produtores, locados de forma a abranger todo o reservatório.

O modelo 3D de propriedades possui contorno estrutural derivado dos horizontes interpretados na sísmica. Para que todos os poços atingissem as camadas do topo do reservatório foram criados a partir de um datum único. Para isso ao invés de determinar um valor em metros para cada poço foi utilizada uma profundidade em células. Entretanto cada célula possui tamanho individualizado e os poços quando convertidos em profundidade podem apresentar comprimentos diferenciados. A Figura 21 mostra uma visão 3D do modelo de propriedades e a localização espacial dos poços. 


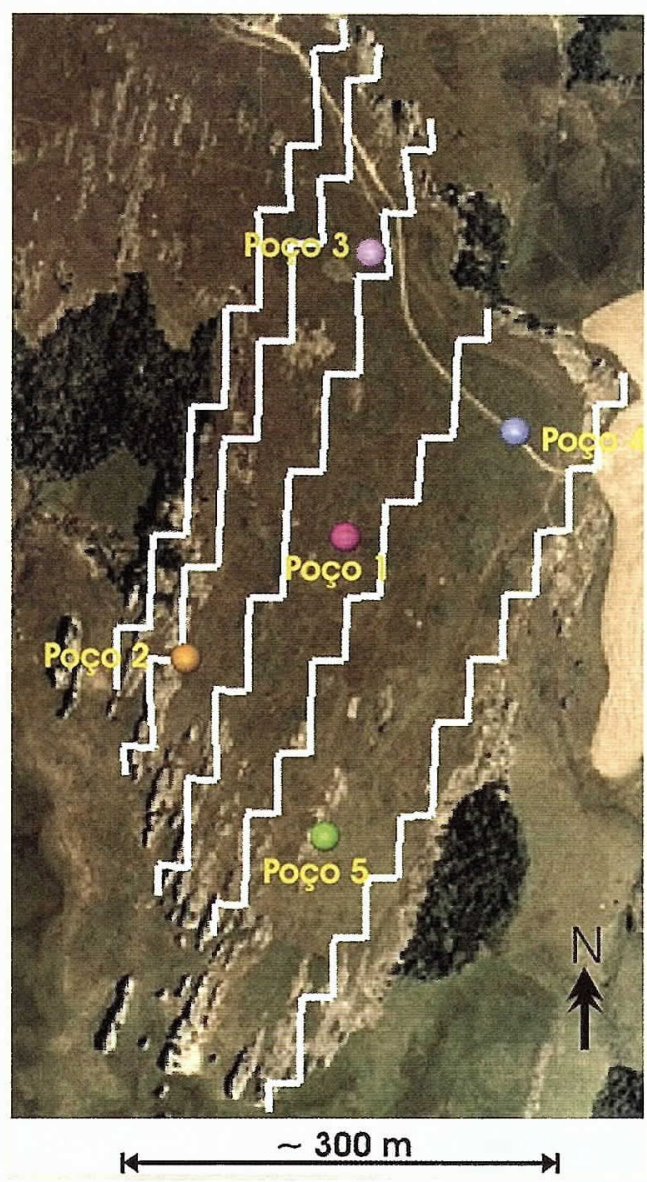

Figura 20 - Fotografia aérea com a localização dos poços e falhas (linhas brancas) utilizados na simulação de fluxo.

Tabela 3 - Locação em IJ dos poços utilizados na simulação de fluxo.

\begin{tabular}{|c|c|c|}
\hline Poço & I & J \\
\hline 1 & 9 & 17 \\
\hline 2 & 4 & 21 \\
\hline 3 & 9 & 8 \\
\hline 4 & 14 & 13 \\
\hline 5 & 8 & 26 \\
\hline
\end{tabular}

Avaliação dos resultados $\mathrm{O}$ parâmetro escolhido para a avaliação qualitativa dos resultados foi a saturação de gás após a simulação. As figuras apresentam o resultado final numa fatia intermediária do topo do reservatório, na mesma profundidade para todas as simulações. Tomou-se como restrição (constraint) que o gás preenchia $100 \%$ da porosidade disponível no início da simulação na fatia analisada, e que o gás expelido do reservatório modelado representaria o gás produzido, em analogia a um campo real.

O modelo sem falhas prevê um comportamento de circulação de fluídos com influência predominante das características petrofísicas da matriz. A distribuição

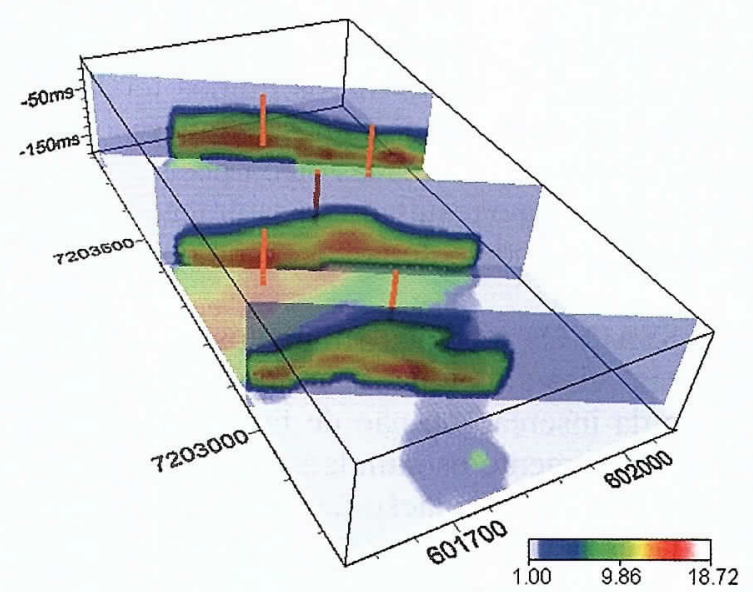

Figura 21 - Modelo de porosidade (\%) com poços em visualização $3 D$.

3D das fácies e forma dos pacotes sedimentares guiaram a depleção do gás durante a simulação. Espera-se que as fácies que contenham as melhores permeabilidades e porosidades sejam as mais depletadas. A figura 22 mostra o modelo com a saturação de gás após a simulação, onde pode ser observada a maior depleção em faixa concêntrica ao redor dos poços.

Para simular as falhas como barreiras de fluxo, determinou-se valor de permeabilidade de $1 \mathrm{mD}$ para as células influenciadas pelo plano de falha, independente da porosidade da rocha matriz. Neste caso, pode até ocorrer armazenamento de fluidos nas células próximas à área de abrangência da falha, entretanto a conectividade entre células de lados opostos da falha será muito baixa. A figura 23 mostra o resultado da saturação de gás após a simulação no modelo com falhas barreiras.

Para simular uma condição mista (condutos/ barreiras), foi atribuído valor de $100 \mathrm{mD}$ para as falhas, semelhante à rocha matriz. A figura 24 mostra o resultado da saturação de gás após a simulação no modelo com falhas intermediárias.

A situação extrema considerou as falhas com

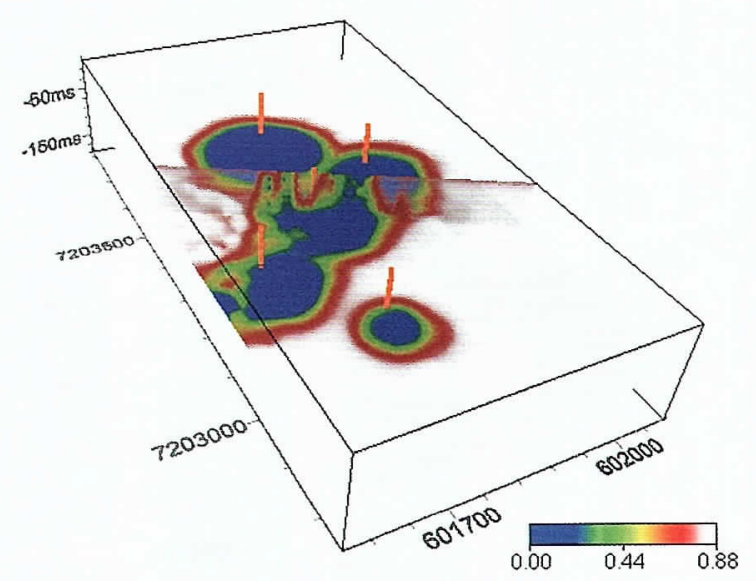

Figura 22 - Saturação de gás após a simulação no modelo sem falhas. 
permeabilidade de $500 \mathrm{mD}$, maior que a permebilidade da rocha matriz. Desta forma os fluídos teriam a tendência de convergir para os planos de falhas ao invés de somente ao longo das camadas ou corpos sedimentares. A figura 25 mostra o resultado da saturação de gás após a simulação no modelo de falhas como condutos.

DISCUSSÃO Os modelos simulados nas 4 situações hipotéticas visaram identificar qualitativamente os impactos da inserção ou não de falhas no modelo geológico. Usualmente os simuladores de fluxo não tem facilidades para a simulação de falhas diretamente nas propriedades petrofísicas nas células influenciadas pelos planos das mesmas, o que influencia os resultados de projeção da produção e até mesmo da viabilidade econômica do campo. Como ponto principal destaca-se a utilização de um software de livre distribuição para simulação multifásica, tipo black-oil.

Os resultados apontaram que o modelo com falhas condutoras resultou em saturação de gás menor que o modelo com falhas barreiras (Fig. 26), indicando

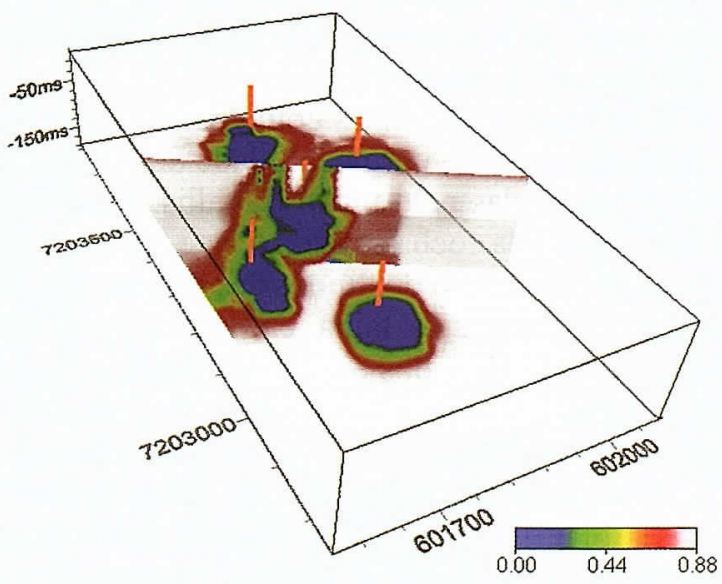

Figura 23 - Saturação de gás após a simulação no modelo falhas barreiras.

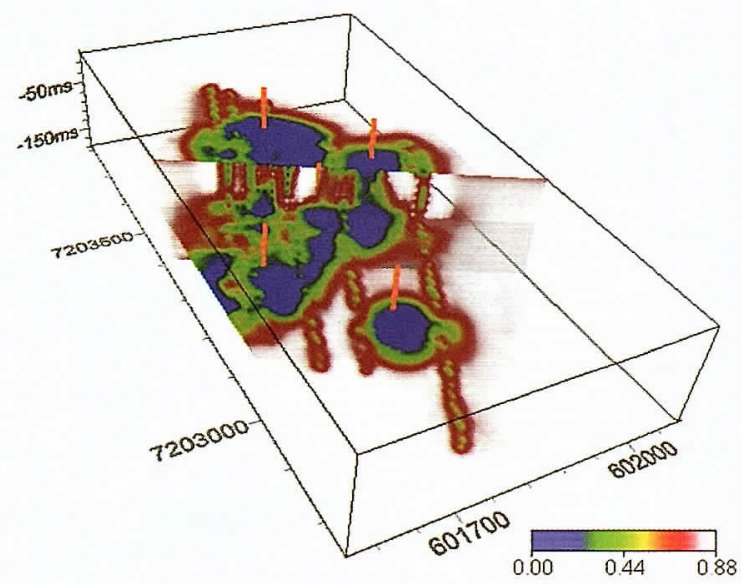

Figura 24 - Saturação de gás após a simulação no modelo falhas condutos/barreiras.

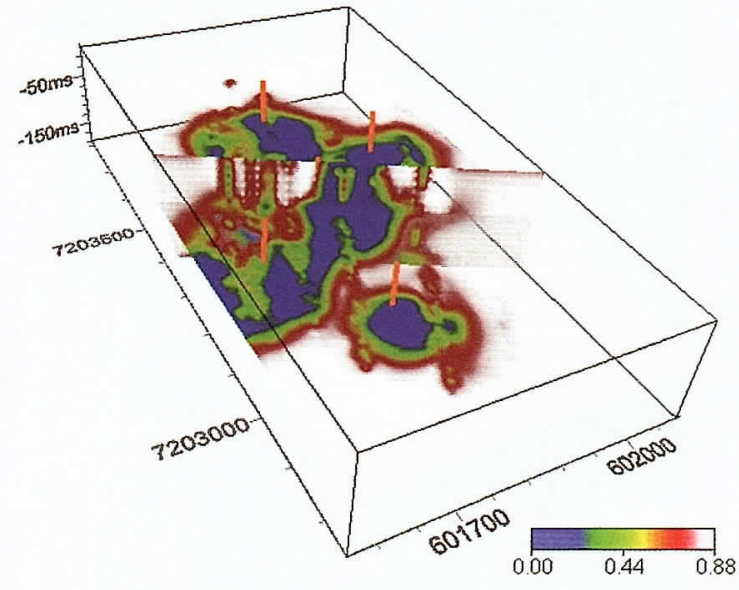

Figura 25 - Saturação de gás após a simulação no modelo falhas condutos.

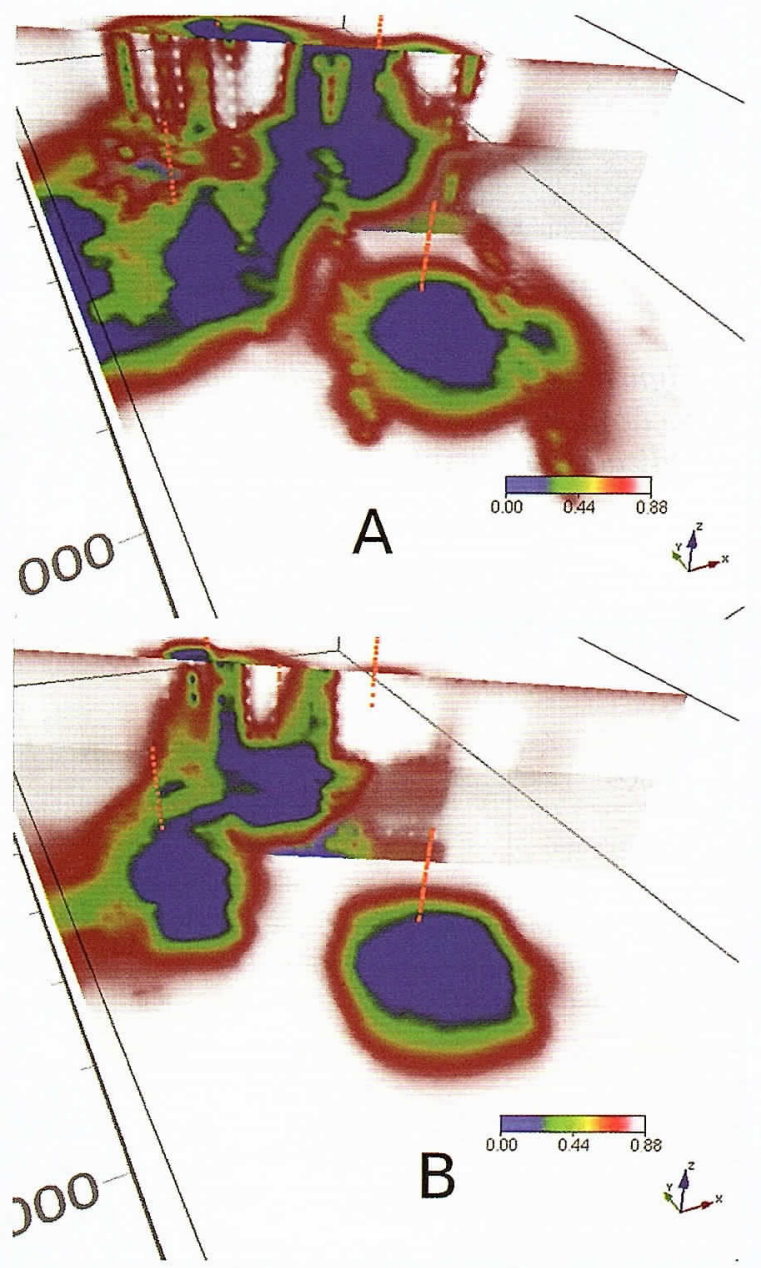

Figura 26 - Diferenças na saturação de gás após a simulação nos modelos condutos (A) e barreiras (B). Janelas de detalhes das figuras 25 e 23 respectivamente $A$ e $B$. $O$ modelo $A$ ocorreu uma produção mais eficiente, depletando o gás de uma área maior que $B$. 
que as altas permeabilidades na faixa de influência das falhas foi suficiente para permitir uma explotação mais eficiente.

CONCLUSÕES A partir da integração de dados de campo, sísmica de alta resolução e estudos auxiliares foi possível gerar um modelo geológico 3D. O local de estudo escolhido apresenta características estratigráficas análogas a um reservatório de hidrocarbonetos em profundidade. Além desta analogia, ocorrem diversas falhas em escala subsísmica, que tornam este modelo análogo muito semelhante ao que se espera de um reservatório fraturado real.

O modelo geológico computacional foi construído a partir de trabalhos de campo e sísmica de alta resolução. Isso permitiu que valores e características descritas no campo pudessem ser distribuídos no modelo. Para o preenchimento do modelo foram utilizadas funções de distribuição vertical nos algoritmos de interpolação para manter o viés estratigráfico. As seqüências e fácies visualizadas no campo foram associadas a valores petrofísicos extraídos de amostras através de ensaios físicos.

Diante de um modelo representativo da geologia do local de estudo foi realizada uma adequação de escalas para agilidade do processamento computacional. Este processo, denominado upscaling, não alterou de forma acentuada a imagem geral da distribuição das propriedades do modelo 3D.

Para comparação qualitativa dos resultados de saturação de gás após a simulação, foram determinadas 4 hipóteses de comportamento hidráulico das falhas: (i) falhas inexistentes, (ii) inibidoras do fluxo $(\mathrm{k}=1 \mathrm{mD})$, (iii) com propriedades mistas entre condutoras e inibidoras $(\mathrm{k}=100 \mathrm{mD})$ e (iv) extremamente condutoras $(\mathrm{k}=500 \mathrm{mD})$. Os resultados das simulações apontaram que a inclusão de fraturas num modelo de reservatório pode modificar significativamente os resultados de produção. O modelo com falhas condutoras obteve um resultado de depleção de gás maior que os outros modelos.

A integração multifonte de dados geológicos e geofísicos, bem como a utilização de aplicativos de livre distribuição, demonstra a possibilidade de desenvolver a modelagem de reservatórios fraturados análogos, com ênfase nas simulações de fluxo.

Agradecimentos Os autores agradecem aos integrantes do Laboratório de Análise de Bacias e Petrofísica (LABAP), da Universidade Federal do Paraná, Departamento de Geologia pela ajuda nos trabalhos de campo. A FINEP e a Petróleo Brasileiro (Petrobrás) pelo apoio financeiro. E a CAPES pela bolsa de doutorado.

\section{Referências}

Bocardi L. (em preparação) Aspectos diagenéticos do Grupo Itararé. Tese de Doutoramento, Departamento de Geologia, UFPR.

BORLAND CODE GEAR 2004. Delphi 5. Ambiente de desenvolvimento de programas computacionais.

Eyles N. \& Miall A.D. 1984. Glacial Facies. In: Walker R.G. (ed.) Facies Model. $2^{\mathrm{a}}$ ed., Geoscience Canada, Reprint Series 1:15-38.

Kraft R.P., Rostirolla S.P., Rigoti A., Appi C.J., Bartoszeck M.K., Campos A.F. de, Lonardelli J.N. 2003. Correlações geofísicas e geológicas para a compreensão da distribuição de propriedades petrofísicas em reservatórios análogos. In: International Congress of The Brazilian Geophysical Society, 8, Rio de Janeiro, CD, 1:1-6.

NATIONAL ENERGY TECHNOLOGY LABORATORY 1998. Boast. Programa para simualção de fluxo 3D.

Rostirolla S.P., Appi C.J., Mancini F., Kraft R.P., Bartoszeck M.K. 2001. Fraturas Controladoras da Migração de Fluidos nos Arenitos Vila Velha, Grupo Itararé, Bacia do
Paraná. Revista Brasileira de Geociências, 31(3):349356.

SCHLUMBERGER 2004. Petrel. Licença acadêmica. Conjunto de programas para modelagem geológica 3D.

Traszkos-Lipski B., Rostirolla S.P. 2005. Microtectônica de bandas de deformação em arenitos Permocarboníferos da Bacia do Paraná. In: Simpósio Nacional de Estudos Tectônicos, 10, Curitiba - PR, Anais, 1:523-525.

Vesely F.F., Assine M.L. 2006. Deglaciation sequences in the Permo-Carboniferous Itararé Group, Paraná Basin, southern Brazil. Journal of South American Earth Sciences, 22:156-168.

Vesely F.F., Rostirolla S.P., Appi C.J., Kraft R.P. 2007. Late Paleozoic glacially related sandstone reservoirs in the Paraná Basin, Brazil. IAAPG Bulletin, 91:151-160.

Manuscrito BR 11

Submetido em 21 de dezembro de 2007 Aceito em 10 de março de 2008 